\title{
Conceptos fundamentales en ecología de hongos del suelo: una propuesta pedagógica y de divulgación
}

\author{
(Fundamental concepts in ecology of soil fungi: a pedagogic and \\ outreach proposal)
}

César Marín ${ }^{1 *}$

${ }^{1}$ Instituto de Ciencias Ambientales y Evolutivas, Universidad Austral de Chile, Valdivia, Chile.

*Autor para correspondencia: cesar.marin@postgrado.uach.cl

RECIBIDO:24 de Mayo de 2018

APROBADO:06 de Junio de 2018

DOI: $10.22370 /$ bolmicol.2018.33.1.1168

LOS AUTORES DECLARAN NO TENER CONFLICTO DE INTERESES

Palabras claves: biogeoquímica, ecología de comunidades, hongos del suelo, jerarquía biológica, micorrizas.

Key words: biogeochemistry, biological hierarchy, community ecology, mycorrhizae, soil fungi.

\section{RESUMEN}

El estudio de los procesos biogeoquímicos implica entender cómo los macro y micro nutrientes que componen los seres vivos se mueven de un componente a otro del ecosistema (incluyendo la atmósfera, organismos, suelo, cuerpos de agua, etc.). Usualmente, una mayor diversidad biótica y una mayor complejidad de las interacciones bióticas y abióticas, resultan en una mayor estabilidad ecosistémica. El rol de los hongos en los ciclos biogeoquímicos se suele estudiar superficialmente, no mucho más allá de sus funciones ecosistémicas generales: descomposición, simbiosis mutualista, y parasitismo. Esta revisión tiene por objetivo ilustrar los conceptos base de los roles ecológicos de los hongos del suelo, que debieran enseñarse en tres públicos objetivo: universitario, tomadores de decisiones, y estudiantes de educa- ción secundaria/público general. En estos públicos, se propone abordar cuatro áreas temáticas: introducción al suelo, ecología de comunidades, interacciones de hongos con otros organismos, $y$ biogeoquímica. Aunque los roles ecosistémicos de los hongos del suelo están bien documentados, su estudio debería partir de la base de que estos afectan y son afectados tanto por variables climáticas, como por características físico-químicas del suelo, y por flujos biogeoquímicos. Los roles ecológicos de los hongos del suelo debieran entenderse en un contexto holístico de integración multidisciplinar, y el nivel de especialización del conocimiento debiera darse hacia niveles superiores de la jerarquía biológica, es decir, conocer más en detalle la ecología de ecosistemas y comunidades de hongos que la de poblaciones y organismos, o que sus procesos bioquímicos y edáficos específicos. 
Conceptos fundamentales en ecología de hongos del suelo: una propuesta pedagógica y de divulgación. - Marín C.

\section{ABSTRACT}

The study of biogeochemical processes involves understanding how the macro and micro nutrients that make up living things move from one ecosystem component to another (including the atmosphere, organisms, soil, waterbodies, etc.). Usually, a greater diversity of biotic diversity and a greater complexity of biotic and abiotic interactions, result in a greater ecosystemic stability. The role of fungi in biogeochemical cycles is usually studied superficially, not much beyond their general ecosystem functions: decomposition, mutualistic symbiosis, and parasitism. The objective of this review is to illustrate the basic concepts of the ecological roles of soil fungi, which should be taught in three target audiences: university students, decision makers, and secondary school students / general public. In these audiences, it is proposed to address four thematic areas: introduction to soil, community ecology, interactions of fungi with other organisms, and biogeochemistry. Although the ecosystemic roles of soil fungi are well documented, their study should be based on the fact that they affect and are affected by climatic variables, physical-chemical soil characteristics, and biogeochemical flows. The ecological roles of soil fungi should be understood in an holistic context of multidisciplinary integration, and the level of specialization of knowledge should be given to higher levels of the biological hierarchy, that is, to know more in detail the ecology of ecosystems and communities of fungi than that of populations and organisms, or than that of their specific biochemical and edaphic processes.

\section{INTRODUCCIÓN}

La biogeoquímica estudia las interacciones entre los compuestos geoquímicos y los organismos. Específicamente, la biogeoquímica estudia cómo los nutrientes que componen los seres vivos se mueven de un componente a otro del ecosistema (incluyendo la atmósfera, organismos, suelo, cuerpos de agua, etc.). Estos nutrientes se clasifican en macro-nutrientes (carbono, oxígeno, hidrógeno, nitrógeno, fósforo, azufre, calcio, magnesio y potasio) y micro-nutrientes (hierro, cobre, zinc, cloro, yodo, entre otros). Se trata entonces de entender cómo se alcanza la estabilidad ecosistémica: mediante interacciones complejas entre sus componentes abióticos y bióticos; usualmente, una mayor diversidad biótica y una mayor complejidad de las interacciones bióticas, resultan en una mayor estabilidad ecosistémica. Diferentes factores abióticos como el clima, la altitud, la latitud, entre muchos otros, afectan la composición, diversidad, y distribución espacial de la biota. A grandes rasgos, las plantas, siendo autótrofas y fotosintéticas, son los principales productores de nutrientes y biomasa; los animales constituyen los principales consumidores; mientras que la descomposición y reciclaje de nutrientes se da por microorganismos como bacterias y hongos.

El rol de los hongos en los ciclos biogeoquímicos se suele estudiar superficialmente. Para su enseñanza, algunas generalidades sobre los hongos deben ser tenidas en cuenta: los hongos tienen características de plantas, bacterias, y animales, pero forman su reino aparte más cercano a los animales que a las plantas; evolutivamente, se separaron de otros linajes hace aproximadamente 1.500 millones de años, pero colonizaron la tierra hace unos 400 millones de años ${ }^{1,2,3}$; son organismos heterótrofos con una pared celular de quitina; incluyen hongos microscópicos como levaduras y mohos, pero también hongos macroscópicos que forman cuerpos fructíferos o setas; crecen vegetativamente y se reproducen mediante la dispersión de esporas en el aire, agua, y en el suelo mediante animales. Aunque actualmente se han descrito unas 120.000 especies de hongos (www.indexfungorum.org), mediante métodos moleculares/bio- 
geográficos se ha estimado que podrían existir entre 2,2 a 3,8 millones de especies ${ }^{4}$.

Dentro de los ecosistemas terrestres, básicamente son tres los roles ecológicos de los hongos: descomposición, simbiosis mutualista, y parasitismo. La descomposición de diferentes formas de materia orgánica (madera, animales muertos, hojarasca, etc.), es uno de los roles más importantes de los hongos, dado que mediante este proceso se da un reciclaje de nutrientes en el ecosistema, algunos provenientes de sustratos de difícil degradación, como la madera ${ }^{5}$. Respecto a las simbiosis mutualistas, además de los líquenes, debe darse un gran énfasis en los hongos micorrícicos, los que hacen simbiosis con el $92 \%$ de las plantas vasculares ${ }^{2}$, y han permitido la colonización y diversificación de las plantas en la tierra ${ }^{2,3}$. Una micorriza es la asociación simbiótica entre hongos del suelo y raíces de plantas vasculares, donde la planta traspasa energía en forma de azúcares y lípidos al hongo ${ }^{6,7,8}$, mientras que las hifas del hongo, al acceder de forma exponencial a mayor volumen de suelo, transfieren agua y nutrientes como fósforo y nitrógeno a la planta, además de conferirle mayor resistencia a sequía, toxicidad, patógenos, salinidad, herbivoría, entre otros. Las micorrizas además son capaces de formar redes que comunican plantas de la misma o diferentes especies, que pueden abarcar incluso decenas de hectáreas de extensión ${ }^{1}$. Finalmente, muchos linajes de hongos parasitan plantas, animales, y a otros hongos, siendo el parasitismo un control ecosistémico de gran importancia ${ }^{9,10}$.

Esta revisión tiene por objetivo ilustrar los conceptos base de los roles ecológicos de los hongos del suelo, que debieran enseñarse en diferentes públicos objetivo (Tabla 1). Para esto, se han seleccionado tres públicos objetivo: universitario, que consiste preferiblemente en estudiantes de postgrado (maestría y doctorado) o de pregrado avanzados; tomadores de decisiones, como fun- cionarios de entidades públicas relacionadas con el sector ambiental/forestal/agrícola o de conservación de áreas protegidas (guardaparques, entre otros); y estudiantes de educación secundaria y 'público general'. Así mismo, se abordan cuatro temas principales: una introducción muy general al suelo, con conceptos base sobre su física, química, biología, y bioquímica; ecología de comunidades, contenido abordado en mayor detalle, con el fin de entender que la diversidad biológica puede ser medida de muchas formas y en muchas escalas espaciales, temporales, y de la jerarquía biológica; interacciones de hongos con otros organismos, particularmente plantas y bacterias; y finalmente, biogeoquímica, donde además de conocer los diferentes ciclos de nutrientes, el objetivo último es comprender el rol y efecto de diferentes tipos de diversidad fúngica en estos ciclos. En la presente revisión cada subtema planteado se tratará sólo para el público universitario, mientras que para los otros dos públicos se plantea una visión general por tema. Nótese que cada uno de estos públicos requiere información diferente, por lo que los contenidos también difieren, no sólo en complejidad sino en el mensaje final entregado (Tabla 1).

\section{INTRODUCCIÓN AL SUELO}

\section{Físico-química del suelo - Nivel Universitario.} El suelo se forma a partir de la meteorización física, química, y biológica del material parental (roca madre; corteza terrestre), de forma continua y dinámica, constituyendo el soporte de la vegetación en el planeta. El suelo se compone de tres fases: sólida, líquida, y gaseosa; la fase sólida domina y se compone de minerales y materia orgánica, la fase líquida corresponde al agua del suelo, y la fase gaseosa corresponde a los poros no ocupados por el agua ${ }^{11}$. Los organismos que habitan el suelo se conocen como edafón, y a la vez que dependen del mismo, también forman el suelo, como se ha estudiado desde Darwin ${ }^{12}$. Las características físico-químicas del suelo pueden variar en po- 
cos centímetros, generando una multiplicidad de micro-hábitats ${ }^{11}$ cuyas características además varían temporalmente. Esto, por supuesto, causa una gran variación en la diversidad del edafón. A nivel de enseñanza universitaria se deberían tener claras unas características base del suelo en cuanto a su física, química, y taxonomía (consultar Métodos de Ecología Vegetal ${ }^{11}$ para mayor información):

- Física: textura, densidad, velocidad de infiltración y percolación del agua, captación de agua gravitacional, humedad del suelo, potencial hídrico matricial del suelo, capacidad hídrica del suelo.

- Química: pH, conductividad eléctrica, potencial redox, capacidad de intercambio catiónico, saturación de bases, contenido y tipo de humus, materia orgánica, carbono total (y sus reservorios por tamaño), carbonatos y bicarbonatos, nitrógeno total (y sus diferentes formas como amonio, nitrato, nitrito, etc.), relación $\mathrm{C} / \mathrm{N}$, fósforo total $\mathrm{y}$ disponible, cationes (aluminio, calcio, magnesio, potasio, sodio), otros nutrientes (como manganeso, hierro, yodo), metales tóxicos (como cadmio, plomo, mercurio).

- Taxonomía: en base a diferencias en las características físico-químicas mencionadas, principalmente respecto a materia orgánica, así como al origen geológico de los suelos, existen diferentes métodos de taxonomía de suelos que son comparados por la FAO en su Base Referencial del Recurso Suelo $2014^{13}$.

A escala global, se ha encontrado que los principales factores edáficos determinando la abundancia y riqueza de todos los tipos de hongos del suelo son el $\mathrm{pH}$ y los contenidos de fósforo y calcio ${ }^{14}$, además de factores ambientales como la precipitación, temperatura promedio anual, distancia al Ecuador, régimen de fuego, y diversidad de plantas ${ }^{14}$. Estos factores edáficos son diferentes cuando se estudian grupos específicos de hon- gos, por ejemplo, para las micorrizas arbusculares (subphylum Glomeromycotina ${ }^{15}$ ), además de la temperatura promedio anual y la precipitación, corresponden también al $\mathrm{pH}$ y al contenido de fósforo, pero además a los contenidos de nitrógeno y carbono orgánico ${ }^{16}$. A escala regional, pueden ser otros los factores edáficos afectando la abundancia y riqueza de diferentes tipos de hongos del suelo $^{17,18,19}$. La riqueza y abundancia de hongos, como las de cualquier tipo de organismos, se ven afectadas además por variables ambientales como la latitud, la precipitación, la temperatura ${ }^{14,16}$, y la altitud $^{19}$, entre otros.

\section{Biología de hongos - Nivel universitario.}

Las características que los hongos comparten con otros eucariotas son: ADN con regiones codificantes y no-codificantes, organelos citoplasmáticos como la mitocondria, membranas que contienen esteroles, ribosomas (tipo 80S), y que almacenan carbono en compuestos como azúcares, disacáridos, y polisacáridos. Con los animales tienen en común que no poseen cloroplastos y son heterótrofos. Al igual que las plantas, los hongos tienen pared celular y vacuolas, y se reproducen sexual y asexualmente; como los helechos y los musgos, producen esporas; y como las algas y los musgos, usualmente tienen núcleos haploides. Los hongos superiores, los euglenoideos y las bacterias, producen el aminoácido L-lisina. La mayoría de los hongos crece en forma de células elongadas y filamentosas, que unidas producen una estructura llamada hifa, sin embargo las levaduras (hongos unicelulares) no producen esta estructura. Algunos hongos, al igual que ciertas especies de plantas y animales, son bioluminiscentes.

Algunas características únicas de los hongos son: algunas levaduras unicelulares se reproducen por esporulación o por fisión binaria. Algunos hongos dimórficos pueden cambiar entre estado de levadura y de hifa. Los hongos son los únicos organismos cuya pared celular está com- 
puesta al mismo tiempo de glucanos (estos se encuentran en la pared celular de las plantas) y quitina (esta se encuentra en el exoesqueleto de los artrópodos). Los hongos producen metabolitos secundarios similares a los de las plantas. Según Tree of Life (http://tolweb.org/fungi), actualmente se reconocen varios phyla de hongos: Basidiomycota, Ascomycota, Glomeromycota, "zygomycota" (término en desuso, pues correspondía a un taxa parafilético), Blastocladiomycota, Chytridiomycota, y Neocallimastigomycota, así como otros phyla no clasificados. Estos phyla se han clasificado principalmente por caracteres morfológicos, y solo recientemente por diferencias genómicas, arrojando incluso hasta 18 phyla de hongos ${ }^{15}$.

\section{Bioquímica del suelo - Nivel universitario.}

Una de las herramientas más usadas para estudiar la actividad biológica en el suelo y las transformaciones de nutrientes dentro del suelo, es la cuantificación de la actividad enzimática. Específicamente, las enzimas se pueden clasificar de acuerdo a su localización: intra y extra-celular; y de acuerdo a su función: hidrolasas y oxidoreduc$\operatorname{tasas}^{20}$. Las hidrolasas, como las polisacaridasas y las proteinasas, transforman sustratos macromoleculares en compuestos más pequeños. Las oxidoreductasas catalizan la transferencia de electrones de una molécula donante o reductora, hacia una molécula aceptora u oxidante. También se han desarrollado técnicas como GeoChip ${ }^{21}$ (http://www. glomics.com/gch-tech.html) que permiten cuantificar directamente los genes procariontes y eucariontes (hasta 180.000 genes) directamente relacionados con los ciclos del carbono, nitrógeno, fósforo, y azufre, además de genes relacionados con la asimilación de metales pesados, antibióticos, y compuestos tóxicos. Además de la cinética enzimática fúngica y expresión de genes fúngicos, cuantificar la biomasa de hongos en el suelo es vital para determinar su actividad bioquímica; esto se puede hacer mediante determinación de ácidos grasos como PLFA y NLFA ${ }^{20,21,22,23}$. Mediante la cuantificación directa de cada una de sus formas químicas, o mediante el uso de métodos como isótopos estables, las transformaciones bioquímicas que mínimamente deberían medirse en el suelo y donde los hongos juegan un rol preponderante, corresponden a las de los ciclos de carbono, nitrógeno, fósforo, y azufre, que pueden ser consultadas en "Soil Biochemistry" 20 y He et $a l^{21}$, entre otros.

\section{Introducción al suelo - Tomadores de decisio- nes.}

Existen muchos tipos de suelos, que varían entre sí en pocos centímetros, y esto determina qué tanto crecerán las plantas (Tabla 1). Además, menos del $2 \%$ de las especies de hongos han sido estudiadas $^{25}$; de los hongos dependen el $92 \%$ de las plantas terrestres para su supervivencia, y diferentes tipos de hongos toleran y permiten que sus plantas simbiontes toleren condiciones edáficas extremas, como exceso de aluminio o cantidades mínimas de fósforo disponible para plantas, como en el sur de Chile ${ }^{17,18,19}$.

\section{Introducción al suelo - Educación secundaria/ Público general.}

En un sólo gramo de suelo pueden existir millones de bacterias y miles de hongos ${ }^{26}$. Estos millones de microorganismos conviven en espacios y poros muy confinados del suelo, donde unos compiten y cooperan con los otros, formando redes tróficas. Diferentes características físicas (densidad, textura, cantidad de agua) y químicas ( $\mathrm{pH}$, carbono, nitrógeno, fósforo, entre otros nutrientes), influyen en qué tipo de microorganismos están presentes; estas características del suelo pueden variar en pocos centímetros. Existen diferentes tipos de hongos en cuanto a su morfología (macro y microscópicos) y funciones (descomponedores, simbiontes, y parásitos), cuyas reacciones bioquímicas son fundamentales para la nutrición vegetal (Tabla 1). 
Conceptos fundamentales en ecología de hongos del suelo: una propuesta pedagógica y de divulgación. - Marín C.

\section{ECOLOGÍA DE COMUNIDADES}

\section{Jerarquía e individualidad biológica - Nivel universitario.}

La ecología se estudia a lo largo de la jerarquía biológica: desde los niveles genético, celular, y organísmico, hasta los niveles poblacional, comunitario, y ecosistémico. Este concepto es particularmente importante en los hongos, donde en muchos casos los límites entre niveles jerárquicos (por ejemplo entre organismos y poblaciones), no son claros. Así, deben tenerse en cuenta los siguientes conceptos cuando se habla de jerarquía biológica, particularmente en hongos.

- Selección multinivel: cuando la selección natural actúa simultáneamente por lo menos en dos niveles de la jerarquía biológica, y los entes de estos niveles cumplen los requisitos para que ocurra evolución por selección natural (variación fenotípica, éxito reproductivo diferencial, y heredabilidad ${ }^{27}$ ), se habla de un proceso de selección multinivel ${ }^{28}$, ${ }^{29}$. Aunque la teoría de selección multinivel es un tema aun controversial en teoría evolutiva, son tres los argumentos que hacen ineludible pensar que este proceso ocurre en la naturaleza ${ }^{28,29,30}:$ i. la naturaleza abstracta del concepto de selección natural $^{31}$, donde esta puede ocurrir en cualquier nivel jerárquico que cumpla los requisitos antes mencio$\operatorname{nados}^{27}$; ii. la existencia de la jerarquía biológica, y el hecho de que para alcanzar la alta complejidad de un gen o un organismo, la selección natural debió actuar primero en entes biológicos menos complejos (inferiores en la jerarquía ecológica); y iii. la abundante evidencia que comprueba empíricamente el proceso de selección multinivele ${ }^{28,29,30}$.

- Individualidad: la definición de qué es un individuo en biología, no es un asunto trivial, particularmente en organismos clonales, simbiontes fuertemente dependientes (como las plantas micoheterotróficas, por ejemplo, que dependen absolutamente de sus micorrizas), microbiomas, y colonias de insectos eusociales, entre otros ${ }^{32,33}$. Sin embargo, y teniendo en cuenta la misma naturaleza abstracta del concepto de selección natural ${ }^{30}$, ${ }^{31}$, podría simplemente decirse que un individuo es todo ente ubicado en un nivel de la jerarquía biológica (de genes a ecosistemas), que cumpla los requisitos para que ocurra evolución por selección natural (variación fenotípica, éxito reproductivo diferencial, y heredabilidad ${ }^{27}$ ).

- Diversidad, de genes a ecosistemas: mencionado lo anterior, pareciera entonces lógico que la diversidad biológica se midiera en todos los niveles de la jerarquía biológica, desde genes a ecosistemas, aunque tradicionalmente el foco ha sido la diversidad de especies. Sin embargo, marcos conceptuales y herramientas estadísticas (índices de diversidad) recientes ${ }^{34}$, permiten cuantificar la diversidad biológica a lo largo de la jerarquía biológica (https://chao.shinyapps.io/iDIP/).

Algunos ejemplos empíricos de selección multinivel en hongos se han registrado en hongos endofíticos ${ }^{35,36}$, levaduras ${ }^{37,38,39,40}$, y Ascomycetes filamentosos ${ }^{41}$. Dentro de los principales phyla de hongos, las micorrizas arbusculares (subphyluym Glomeromycotina) presentan una biología celular bastante particular, ya que una célula puede tener decenas de núcleos, y el ADN de estos núcleos puede variar altamente ${ }^{41,42}$. Sanders $2002^{41}$ y Rosenddahl $2008^{42}$, discuten sobre el concepto de individualidad en hongos, particularmente en micorrizas arbusculares: un individuo se puede definir tanto fisiológica como genéticamente ${ }^{42}$. El micelio que crece de una espora (sea sexual o asexual), o un fragmento de hifa, en términos físicos o fisiológicos, constituirán un individuo. Sin embargo, la unidad genética o evolutiva se constituirá por fragmentos de hifas o esporas genéticamente idénticas que surgen de la reproducción y que pueden o no estar conectadas espacialmente ${ }^{42}$. Un ejemplo bastante conocido de este fenómeno, donde fragmentos de hifas y cuerpos fructíferos genéticamente idénticos (es decir, un sólo individuo), que cubren grandes áreas, está dado por el 
Conceptos fundamentales en ecología de hongos del suelo: una propuesta pedagógica y de divulgación. - Marín C.

hongo parásito de plantas Armillaria ostoyae, que cubre un área de 890 hectáreas de bosques de $\mathrm{Se}$ quoia sempervirens, en Oregon, Estados Unidos ${ }^{43}$. Una discusión que poco se ha dado respecto a la individualidad de hongos, corresponde a ¿qué es un individuo en las relaciones micorrícicas?. Podría proponerse que existe un gradiente de individualidad: desde relaciones altamente dependientes entre sí, donde las plantas parasitan al simbionte micorrícico, como en las plantas micoheterotrófi$\operatorname{cas}^{44,45,46,47}$ y obtienen sus nutrientes totalmente mediante el hongo y no mediante la fotosíntesis, pasando por las micorrizas arbusculares, hongos que dependen absolutamente de la planta (simbiosis obligada), que siempre tienen una relación mutualista con la misma, y de los que no se conocen especies de vida libre ${ }^{16}$, hasta las ectomicorrizas, que bajo ciertas condiciones climáticas, edáficas, o de interacciones biológicas pueden pasar a ser hongos parásitos o saprofíticos ${ }^{48,49,50,51,52,53,54,55}$. Finalmente, pareciera que no se ha implementado una cuantificación de la diversidad fúngica en los diferentes niveles de la jerarquía biológica ${ }^{34}$.

\section{Diversidad alfa - Nivel universitario.}

La diversidad alfa es la diversidad de especies promedio en sitios o hábitats (o muestras) a escala lo$\mathrm{cal}^{56}$. En contraste, la diversidad beta corresponde a la relación entre la diversidad local y regional de especies, y la diversidad gamma corresponde a la diversidad total de especies a escala de paisaje ${ }^{56}$. Aunque usualmente se reportan índices de diversidad como Shannon (H') y Simpson (1-D1) como medida de diversidad alfa, estos índices corresponden más a una medida de estructura comunitaria, ya que su cálculo considera simultáneamente la abundancia y la riqueza de especies ${ }^{56}$. Algunas medidas que reflejan mejor la diversidad alfa son: la riqueza de especies, la contribución alfa, beta, y gamma al índice de Simpson (1-D1) ${ }^{56}$, los perfiles de Rényi ${ }^{56}$, y el número efectivo de especies o índice $\mathrm{Chao}^{34}$ (https://chao.shinyapps.io/iDIP/). Respecto a la literatura de diversidad fúngica, nor- malmente son reportados índices como riqueza, Shannon (H') y Simpson (1-D1), entre otros, tanto a escala global ${ }^{14,16}$, como local ${ }^{17,18,19}$.

\section{Otros tipos de diversidad - Nivel universitario.}

Las comunidades biológicas, y particularmente las comunidades de microorganismos como los hongos del suelo, poseen una gran complejidad intrínseca. Es así que, para caracterizar una comunidad fúngica no es suficiente con cuantificar la diversidad alfa, las siguientes propiedades o tipos de diversidad también debieran considerarse.

- Estructura comunitaria: hace referencia a un índice o parámetro estadístico que incorpora simultáneamente la riqueza (número de especies) y abundancia (número de individuos por cada especie) de una comunidad biológica ${ }^{56}$. Algunos de los índices de estructura comunitaria más comúnmente usados, incluyen ${ }^{56}$ : Shannon (H'), Simpson (1-D1), Simpson inverso (D2), Equitatividad (E'), y Berger (BP). Las diferencias entre estructuras comunitarias de diferentes sitios o muestras se pueden cuantificar mediante distancias ecológicas como la distancia Euclidiana, Bray-Curtis, y Kulczynski ${ }^{56}$. Además, la estructura comunitaria se puede cuantificar por modelos de ordenación multidimensionales, que son más precisos y capturan de mejor forma la complejidad comunitaria, comparados a los índices de diversidad. Algunos de los modelos de ordenación más usados, incluyen ${ }^{56}$ : análisis de componentes principales (PCA), escalamiento multidimensional no-métrico (NMDS), análisis de redundancia basado en distancia (db-RDA), y análisis de correspondencia canónica (CCA). La mayoría de los estudios ecológicos de diversidad fúngica del suelo incorporan una o varias de estas medidas de estructura comunitaria ${ }^{14,16,17,18,19}$, aunque estudios desde disciplinas como la agronomía y la geología, suelen usarlos menos ${ }^{19,57}$.

- Diversidad funcional: se puede definir como "un componente de la diversidad que generalmente se refiere al rango de cosas que los organismos ha- 
cen en las comunidades o en ecosistemas" ${ }^{\prime 58}$. Usualmente, para cuantificar la diversidad funcional, se miden una serie de caracteres funcionales dentro de cada población componiendo una comunidad ${ }^{56}, \mathrm{y}$ se calculan varios índices de cómo varía este carácter dentro y entre comunidades ${ }^{56}$. Sin embargo, en comunidades microbianas, como las comunidades de hongos del suelo, se dificulta medir caracteres, por lo que desde un principio se ha acudido a cuantificar el consumo microbiano de nutrientes como el carbón y otros (técnica BioLog ${ }^{59}$ ), su actividad enzimática, la presencia de genes funcionales (técnica GeoChip ${ }^{21}$ o secuenciación de los genomas completos de todos los microrganismos ${ }^{60}$ ), y más recientemente la medición en el suelo de ciertas 'omics', como metatranscriptómica y metaproteómica $^{60}$.

- Diversidad filogenética: medida de diversidad que incorpora diferencias filogenéticas entre especies. Corresponde "a la suma de las longitudes de todas las ramas [de un cladograma o árbol filogenético] que son miembros de la ruta de extensión mínima [distancia mínima entre dos nodos] correspondiente"61. En términos sencillos, la diversidad filogenética cuantifica si el árbol filogenético local de una comunidad tiende a tener muchas o muy pocas especies hermanas; es muy plausible que las especies hermanas tengan funciones y nichos ecológicos similares. Por ejemplo: si tenemos una comunidad A y una comunidad B, donde la comunidad A se compone de cinco especies inmediatamente emparentadas, y la comunidad $\mathrm{B}$ se compone de cinco especies muy poco relacionadas filogenéticamente, aunque estas dos comunidades tendrán la misma riqueza, serán en todo caso comunidades muy diferentes; esta diferencia es cuantificada por medidas de diversidad filogenética. El índice de diversidad filogenética más comúnmente utilizado corresponde al Faith's Phylogenetic Diversity (PD), pero existen muchos otros ${ }^{56,61}$. La diversidad filogenética se ha usado ampliamente en macro-organismos como indicador de procesos ecosistémicos ${ }^{56}$, y se está empezando a usar en hongos del suelo ${ }^{62}$.
- Redes de co-ocurrencia: si en una comunidad, las abundancias de dos especies están siempre altamente correlacionadas, se dice que estas especies co-ocurren ${ }^{63}$. Así, por ejemplo, si la abundancia de la especie $\mathrm{x}$ está directamente relacionada con la abundancia de la especie y, e inversamente relacionada con la abundancia de la especie $\mathrm{z}$, se dice que las especies x y y co-ocurren (o tienen interacciones ecológicas positivas o cooperativas), mientras que las especies x y z se repelen (o tienen interacciones ecológicas negativas o de competencia). Este tipo de análisis de redes de interacciones ecológicas en microorganismos es muy reciente, y sus bases conceptuales están dadas en Barberán et al $2012^{63}$, Berry\&Widder $2014^{64}$, Williams et al $2014^{65}$ y Morales-Castilla et al 201566. Sólo recientemente esta aproximación se ha usado en microbiomas humanos ${ }^{67}$, y en bacterias del suelo tras regímenes de fuego ${ }^{68}$.

\section{Preguntas en ecología de comunidades fúngicas - Nivel universitario.}

Al realizar estudios de ecología de comunidades de hongos del suelo, son muchas las preguntas que pueden surgir, por ejemplo ¿qué variables climáticas, edáficas, y bióticas (de otros organismos y de hongos) afectan uno o más tipos de diversidad (alfa, funcional, y filogenética, y estructura y redes) de hongos del suelo? Se pueden incluir una, varias, o todas las variables climáticas, edáficas, $\mathrm{y}$ bióticas, y una, varias, o todas las medidas de diversidad, de uno, varios, o todos los grupos de hongos del suelo. Se pueden clasificar los hongos del suelo en gremios funcionales (patógenos de plantas, animales, y hongos; micorrizas arbusculares, ectomicorrizas, micorrizas ericoides, y líquenes; saprófitos, podredumbre blanca, y podredumbre marrón), mediante métodos bioinformáticos ${ }^{69}, \mathrm{y}$ formular estas preguntas sobre los gremios fúngicos de interés. Cualquiera sea la pregunta, deben tenerse en cuenta las siguientes consideraciones mínimas respecto al muestreo y análisis de datos, especialmente cuando se trabaje en metagenómica de hongos del suelo. 
Conceptos fundamentales en ecología de hongos del suelo: una propuesta pedagógica y de divulgación. - Marín C.

- Muestreo de suelos para análisis físico-químicos: dependiendo de los objetivos de estudio, se pueden realizar varios tipos de muestreo de suelo. En primer lugar, se debe examinar qué fase del ambiente edáfico se va a examinar: el suelo sensu stricto ('bulk soil', es decir, el suelo que no está influenciado por la presencia de raíces); el suelo rizosférico (el suelo que rodea las raíces; al hacer muestreo, se puede decir que es el suelo que queda pegado a las raíces); y el compartimento endofítico (bacterias y hongos que están dentro de la raíz). Así mismo, se debe evaluar qué horizonte u horizontes del suelo se analizarán: $\mathrm{O}$ (orgánico), A (el más comúnmente analizado), E, B, C, o R. Por lo general, la mayoría de muestreos se centran en el bulk soil y en el horizonte A; pero de nuevo, esto dependerá de la pregunta de estudio. Respecto a cuántas muestras se deben procesar, una opción es analizar cada muestra de forma independiente, y otra opción es una muestra mixta por parcela. Esto también dependerá de la pregunta, pero lo importante es siempre tener al menos tres réplicas. Como ejemplo: si se muestrean 10 lugares al azar en 10 parcelas, bajo el muestreo independiente se obtienen 100 muestras (sin réplicas biológicas), o 300 muestras (con réplicas biológicas); si en las mismas 10 parcelas se hacen muestras mixtas, se obtienen 10 muestras en total, o 30 muestras incluyendo réplicas biológicas. Cuando se hace una muestra mixta (mezclando muy bien las submuestras de suelo), es indispensable realizar las réplicas técnicas (que se obtienen después de mezclado el suelo), ya que la variación puede ser alta. Los análisis físico-químicos clásicos de suelo son: potencial Redox, $\mathrm{pH}$, conductividad eléctrica (estos tres se suelen medir con un mismo instrumento, $\mathrm{pH}-$ metro), porcentaje de $\mathrm{C}$ y N (mediante $\mathrm{CN}$ Analyzer), $\mathrm{P}$ total, $\mathrm{P}$ disponible para plantas, $\mathrm{Al}, \mathrm{Ca}, \mathrm{K}$, $\mathrm{Na}, \mathrm{y} \mathrm{Mg}$ (mediante ICP-OES, inductively coupled plasma atomic emission spectroscopy); se pueden medir otros elementos como $\mathrm{Cd}, \mathrm{Fe}$, y $\mathrm{Mn}^{11}$, también mediante ICP-OES. Los análisis de suelo, en su mayoría, se hacen sobre suelo secado a tempe- ratura ambiente, tamizado, y en algunos casos procesado a partículas finas ${ }^{11}$.

- Muestreo de suelos para extracción de ADN fúngico: debe corresponder, obviamente, al mismo tipo de muestreo y a la misma muestra seleccionada para análisis químico de suelos, de tal forma que la estructura comunitaria de hongos se pueda relacionar con las variables físico-químicas del suelo. Las muestras para extracción de ADN deben estar lo más frescas posible (inmediatamente después del trabajo de terreno), conservadas con golpe de nitrógeno líquido y a $-80^{\circ} \mathrm{C}$ (especialmente si se realizarán otros procedimientos como metaproteómica o metatranscriptómica $\left.{ }^{60}\right)$. Muestreos para actividad enzimática o consumo de nutrientes difieren ${ }^{11}$. Si el objetivo es solamente extraer ADN fúngico (y no $\mathrm{ADN}$ de otros organismos, o muestreo para otros análisis), también es posible secar y conservar el suelo tamizado (a $2 \mathrm{~mm}$ ) mediante silica ge $1^{14,16}$.

- ¿Qué plataforma de secuenciación utilizar?: la respuesta corta, al menos para metagenómica de hongos del suelo (acá es importante la especificidad), es Illumina, ya sea Illumina Miseq (principalmente) o Illumina Hiseq ${ }^{70}$. Los detalles del porqué se encuentran en los Field Guides para NGS de The Molecular Ecologist (http://www.molecularecologist.com/2016/03/2016-ngs-field-guide-preview/), donde se muestra que cada año van cambiando un poco las plataformas, aunque en general, Illumina es la que más fuerza ha tomado en los últimos años (sin embargo, ver discusiones y pruebas en hongos del suelo de plataformas muy recientes como PacBio e IonTorrent ${ }^{71}$ ). La pirosecuenciación (454-pyrosequencing) también tuvo su auge, pero su uso se ha descontinuado. La relación costo/ No. Secuencias de Illumina es bastante buena, al igual que la calidad del trabajo producido. Illumina genera archivos de extensión .fastq, donde además del ID de la secuencia y la secuencia, se presenta un indicador de la calidad de lectura de cada una de las bases (i.e., una serie de indicadores que dan 
Conceptos fundamentales en ecología de hongos del suelo: una propuesta pedagógica y de divulgación. - Marín C.

cuenta de la calidad de detección de cada base respectiva, en el mismo orden de la secuencia). Esto permite hacer controles de calidad más estrictos que en otras plataformas.

- ¿Qué región del ADN fúngico utilizar?: al estudiar comunidades de hongos, las regiones típicamente utilizadas son: LSU, ITS1, ITS2, SSU, y gen de tubulina, entre otros. Algunas de éstas regiones (SSU rRNA) han servido, por ejemplo, tanto para sistemática filogenética como para ecología de comunidades de subphylum como Glomeromycotina ${ }^{16}$, ${ }^{72}$, que tiene su base de datos moleculares propia (https://maarjam.botany.ut.ee). Otros marcadores como el ITS1 o el LSU en general sirven bastante bien para Ascomycota, Basidiomycota, zygomycota e incluso Chytridiomycota, pero no para Glomeromycotina. Hasta hace muy poco, pareciera que no se tenía una región que fuera igualmente buena para todos los phyla de hongos, y que en general no se pudiera hacer una ecología molecular de comunidades de hongos. Trabajos recientes ${ }^{73,74}$, dan cuenta que la región más indicada para reflejar toda la diversidad fúngica comunitaria, es el ITS2. El marcador molecular reverse sugerido para la región ITS2 es el ITS4, los marcadores moleculares forward sugeridos para esta región son el fITS7 y gITS $7^{75}$, los que pueden ser utilizados de forma independiente, o al mismo tiempo (ésta última opción es recomendada para lograr una mayor exactitud de secuenciación). La base de datos UNITE (https://unite.ut.ee/), agrupa los datos moleculares de todos los tipos de hongos que se encuentran en múltiples bases de datos moleculares, y se basa en la región ITS (tanto ITS1 como ITS2) 74 .

- Bioinformática: el pipeline bioinformático para analizar secuencias de ITS fúngico (ITS1 e ITS2) provenientes específicamente de la plataforma Illumina Miseq se denomina PIPITS ${ }^{69,76}$ (tutoriales en: https://github.com/hsgweon/pipits y en: https:// github.com/UMNFuN/FUNGuild).

- Análisis estadísticos de comunidades: dependerán enormemente de los objetivos de estudio. Pero hay algunos parámetros descriptivos básicos, como índices de diversidad, perfiles de Rényi, ordenaciones, y Test de Mantel $^{56}$. Primero, es primordial hacer curvas de acumulación (exactas o randomizadas) de especies, ya sea totales, por muestra, o de acumulación de individuos, para examinar si el muestreo fue exitoso ${ }^{56}$. Se recomienda además hacer un gráfico de dispersión donde en el eje X esté el número de secuencias y en el eje $\mathrm{Y}$ el número de OTUs (operational taxonomic units); si la relación es positiva, primero se deben estandarizar los datos por rarefacción antes de proseguir. Si la relación no es significativa se puede trabajar con la misma matriz. Los índices de diversidad básicos son: riqueza de especies (S), contribución alfa, beta, y gamma al índice de Simpson (1-D1) ${ }^{56}$, perfiles de Rén$\mathrm{yi}^{56}$, número efectivo de especies o índice $\mathrm{Chao}^{34}$, Shannon (H'), Simpson (1-D1), Simpson inverso (D2), Equitatividad (E'), y Berger (BP), los que se pueden calcular siguiendo instrucciones en Kindt \& Coe $2005^{56}$. Aunque poco utilizados, los perfiles de Rényi permiten ver gráficamente la diversidad alfa y la equitatividad o igualdad entre varios sitios/muestras, mostrando qué tan equitativamente se distribuye la abundancia entre las especies (contrario a dominancia $)^{56}$. La diversidad alfa expresada por estos perfiles está directamente relacionada con la riqueza, y con los índices de Simpson y Shannon. La elección de modelos de ordenación sin restricción (PCA y NMDS, se usan cuando sólo se tiene la matriz de abundancia de especies por sitio/muestra) y restringidos (db-RDA y CCA, se usan cuando además de la matriz de especies se tiene una matriz de variables ambientales), depende de qué tan bueno fue el muestreo, de la cantidad y tipo de variables ambientales (climáticas-edáficas) medidas, y de la filosofía estadística a utilizar (si se aboga por modelos que dejan nada sin explicar, como los restringidos, o si se deja abierta la posibilidad para fenómenos no explicados, como los modelos sin restricción). El test de Mantel estándar y el test de Mantel parcial, respectivamente, permiten ver la relación entre la distancia geográfica y la 
distancia ecológica, y entre la distancia ambiental y la distancia ecológica ${ }^{56}$. Entendiéndose las distancias ecológicas y ambientales, como medidas de disimilaridad (Euclidiana y/o Bray-Curtis por lo general) entre sitios/muestras, medidas dadas por su matriz comunitaria y matriz ambiental, respectivamente ${ }^{56}$. Los métodos de cálculo de diversidad funcional y filogenética se encuentran en Swenson 201476; la forma de graficar y calcular redes de coocurrencia se encuentra en Barberán et al 2012 $2^{63}$, Berry \& Widder $2014^{64}$, Williams et al $2014^{65} \mathrm{y}$ Morales-Castilla 201566. Los análisis estadísticos de preguntas específicas en ecología de comunidades, se pueden realizar mediante regresiones lineales simples o múltiples, ANOVAs, MANOVAs, Test de medias, Test de Tukey, modelos lineales simples o mixtos, GLM, inferencias bayesianas, modelos de árboles de decisiones, inferencias multimodelo, modelos no-paramétricos, modelamiento estructurado de ecuaciones, entre otros ${ }^{56}$. Algunos de los paquetes estadísticos más comúnmente utilizados para realizar este tipo de análisis, corresponden a vegan, BiodiversityR, ape, MASS, gam, randomforest, sem, car, vegan, ggplot2, phytools, abind, geiger, picante, nlme, ecodist, y ade4, entre muchos otros, del software estadístico R Studio ${ }^{77}$. Algunos manuales estadísticos de estos métodos son: Kindt \& Coe $2005^{56}$, Swenson $2014^{76}$, Wickham $2016^{78}$, Albert $2007^{79}$, Stevens $2009^{80}$, Ebveritt \& Hothorn $2011^{81}$ y Paradis $2012^{82}$.

\section{Ecología de comunidades - Tomadores de deci- siones.}

De acuerdo a tratados y convenios internacionales a los que la mayoría de los países se han suscrito, como el Convenio sobre la Diversidad Biológica de las Naciones Unidas (ONU; 1992) ${ }^{83}$, el Tratado Internacional sobre los Recursos Fitogenéticos para la Alimentación y la Agricultura de la Organización para la Agricultura y la Alimentación (FAO) de la ONU (2001) ${ }^{84}$, o los Objetivos de Desarro1lo Sostenible de la ONU $(2015)^{85}$, la diversidad biológica implica o incluye la diversidad a niveles genético, organísmico, poblacional, comunitario, y ecosistémico. Por ende, la 'diversidad biológica', incluyendo la de los hongos, en el escenario de derecho internacional al que suscriben los países, debe estudiarse y conservarse en todas estas escalas.

\section{Ecología de comunidades - Educación secunda- ria/Público general.}

Al público general debe simplemente explicarse el concepto de la jerarquía biológica, e indicársele que la biodiversidad se cuantifica desde genes hasta ecosistemas. Como ejemplo particular de los hongos, se puede indicar que un sólo individuo de hongo (Armillaria ostoyae) cubre un área de 890 hectáreas de bosques de Sequoia sempervirens, en Oregon, Estados Unidos ${ }^{43}$, es decir, que su diversidad genética y organísmica en dicha área es muy baja, pero en dicha área cubre una gran diversidad ecosistémica. O ejemplos mencionados anteriormente, como en las micorrizas arbusculares, donde una sola espora puede tener decenas de núcleos, y el ADN de estos núcleos puede variar altamente ${ }^{41}$, ${ }^{42}$, es decir, puede existir una alta diversidad genética y baja diversidad organísmica (una sola espora), aunque en general los niveles de endemismo de las micorrizas arbusculares son bastante bajos a escala global ${ }^{16}$.

\section{INTERACCIONES DEL EDAFÓN}

\section{Interacciones de hongos con otros hongos - Ni- vel universitario.}

Las interacciones entre diferentes gremios funcionales (patógenos de plantas, animales, y hongos; micorrizas arbusculares, ectomicorrizas, micorrizas ericoides, y líquenes; saprófitos, podredumbre blanca, y podredumbre marrón) de hongos del suelo, por lo general han sido poco estudiadas. Para las micorrizas, algunas propuestas dan cuenta de sus interacciones y patrones biogeográficos ${ }^{86,87}$, recientemente $^{2}$ se ha descrito que el $72,0 \%$ de las plantas vasculares tienen asociaciones con mico- 
Conceptos fundamentales en ecología de hongos del suelo: una propuesta pedagógica y de divulgación. - Marín C.

rrizas arbusculares, el 2\% con ectomicorrizas, el $1.5 \%$ con micorrizas ericoides, el $10 \%$ con micorrizas orquioides, el $7 \%$ de las plantas vasculares pueden o no asociarse con micorrizas arbusculares, y sólo el $8 \%$ de las plantas vasculares viven sin micorrizas ${ }^{2}$. En escala evolutiva, las micorrizas arbusculares aparecieron primero $^{2,3}$, hace aproximadamente unos 450 millones de años ${ }^{2}$, mientras que las ectomicorrizas aparecieron hace unos 145,5 millones de años ${ }^{2}$. Y aunque los hongos micorrícicos arbusculares son tan solo aproximadamente 300 especies $^{16}$ (http://www.mycobank. org/), hacen simbiosis con el $72 \%$ de las plantas vasculares ${ }^{2}$, mientras que los hongos ectomicorrícicos son $>20.000$ especies $^{87}$, pero hacen simbiosis con tan solo el $2 \%$ de las plantas vasculares ${ }^{2}$ que en todo caso corresponden a bosques de Pinaceae, Nothofagus, y otros tipos de vegetación muy extendida tanto en el hemisferio norte, como en el sur, respectivamente. En consecuencia, los hongos micorrícicos arbusculares se caracterizan por ser más antiguos ${ }^{2,3}$, tener una baja diversidad $\mathrm{y}$ endemismo ${ }^{16}$, baja especificidad de la simbiosis, pero por estar asociados con la mayoría de plantas vasculares ${ }^{2}$; en contraste, las ectomicorrizas son más recientes, presentan una alta diversidad, endemismo, y especificidad de la simbiosis ${ }^{14,87}$, pero se asocian sólo con el 2,0\% de las especies de plantas vasculares terrestres ${ }^{2}$ (que cubren grandes extensiones en ambos hemisferios).

Como se señaló anteriormente, bajo ciertas condiciones las ectomicorrizas pueden pasar a ser hongos saprofíticos, a competir con los hongos saprofíticos (degradando los mismos componentes de la materia orgánica del suelo), y/o a parasitar a las plantas hospederas ${ }^{48,49,50,51,52,53,54,55}$. Recientemente se ha descrito que bajo escenarios de disturbios ambientales, los hongos parásitos de plantas se verían favorecidos sobre las ectomicorrizas y los hongos saprofíticos ${ }^{17}$. Finalmente, los hongos que parasitan a otros hongos han sido muy poco estudiados ${ }^{88}$.

\section{Interacciones de hongos con plantas - Nivel universitario.}

Las interacciones de los hongos del suelo con las plantas se circunscriben dentro de las tres grandes funciones ecológicas de los hongos en ecosistemas terrestres: descomposición, simbiosis, y parasitismo. Para entender los mecanismos fisiológicos y ecológicos de la descomposición de la materia orgánica y litera por parte de hongos, se puede consultar Berg \& Laskowski $2006^{89}$, Berg \& McClaugherty $2014^{90}$ y Graça et al $2005^{91}$; algunas generalidades de la simbiosis micorrícica se encuentran en Varma $2008^{92}$ y Smith \& Read $2008^{93}$, o en Varma et al $2017^{94}$ respecto a su fisiología, en Varma et al $2017^{95}$ sus funciones generales, o en Wu $2017^{96}$ sus funciones de tolerancia que confiere a la planta respecto a estresores ambientales como sequía, toxicidad, parasitismo, entre otros. Algunas generalidades de los mecanismos de parasitismo de hongos a plantas se pueden consultar en Mendgen et al $1996^{97}$, Dean et al $2012^{98}$ y Doehlmann $2017^{99}$. Una línea de investigación reciente, concierne al efecto de la estructura y tipo de asociación micorrícica de la comunidad vegetal, sobre la química edáfica y diversidad de hongos del suelo, sus patrones biogeográficos, y sus funciones eco-

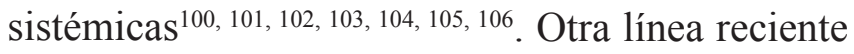
de investigación está dada por el efecto facilitador que algunas especies de ectomicorrizas tendrían en las invasiones biológicas de plantas como Pinus y otros, siendo tanto los simbiontes vegetales como los hongos, considerados como especies invaso$\operatorname{ras}^{107,108,109,110,111 .}$

Interacciones de hongos con Bacteria, Archaea, animales - Nivel universitario.

La micorizósfera es el compartimento del suelo donde ocurren la mayoría de las interacciones edáficas entre hongos, bacterias, y ocasionalmente organismos del Reino Archaea ${ }^{92,}$,3, 94, 95, 96. Aunque la mayoría de estas interacciones se han reportado como positivas, por ejemplo al promover el crecimiento vegetal ${ }^{112,}{ }^{113}$, también algunas interaccio- 
nes bacterias-hongos causan patogénesis ${ }^{114}$, y en todo caso están circunscritas dentro de una red trófica más amplia y compleja, que incluye a animales de gran importancia ecológica en los ciclos de nutrientes del suelo, como los nemátodos ${ }^{115} \mathrm{y}$ lombrices de tierra ${ }^{116,117,118,119}$. En general, mediante mecanismos como el quorum sensing y la integración fisiológica de las bacterias a las funciones de la simbiosis micorrícica (células bacterianas siendo transportadas dentro de las hifas ${ }^{120}$ ), se puede entender la rizósfera completa, incluyendo plantas, hongos, bacterias, y otros microorganismos, como un meta-organismo ${ }^{121}$; esta interacción es vital, ya que se ha demostrado que por ejemplo, los hongos promueven la toma de nutrientes y agua por parte de bacterias en ambientes muy $\operatorname{secos}^{122}$. En cuanto a las interacciones entre hongos micorrícicos y herbívoros, parece no haber un patrón universal, puesto que se han observado tanto efectos positivos como negativos de diferentes tipos de micorriza sobre la intensidad y tipo de herbivoría ${ }^{123,124,125}$.

\section{Interacciones del edafón - tomadores de deci- siones.}

La rizósfera es un compartimento complejo del suelo donde raíces de plantas, hongos, bacterias, y otros microorganismos del suelo interactúan de forma compleja. Específicamente, los hongos descomponen hojas, materia orgánica, y organismos muertos contribuyendo al ciclo de nutrientes; también hacen simbiosis con las raíces de las plantas, denominadas micorrizas, que son vitales para la nutrición vegetal, ya que de esta simbiosis depende el 92\% de las plantas terrestres 2 ; y parasitan animales, plantas, y a otros hongos (Tabla 1).

\section{Interacciones del edafón - Educación secunda- ria/Público general.}

La rizósfera consiste en el suelo que está inmediatamente alrededor de las raíces de las plantas terrestres; en este compartimento del suelo, una gran cantidad de interacciones ecológicas ocurren entre plantas, animales, hongos, bacterias, y otros microorganismos del suelo: interacciones positivas o de cooperación o mutualismo, como ocurre entre hongos del suelo y raíces de la planta, al formar una micorriza, donde ambos organismos dependen en su supervivencia del otro, $\mathrm{u}$ otras interacciones positivas como entre micorrizas y bacterias, que ayudan a promover el crecimiento vegetal ${ }^{112}$, ${ }^{113}$, pero también interacciones negativas, como el parasitismo de hongos hacia animales, plantas, $\mathrm{y}$ otros hongos. Adicionalmente, los hongos constituyen el principal reciclador a nivel ecosistémico, al descomponer las hojas que se caen de los árboles o litera, y permitir a estos nutrientes regresar a la planta.

\section{BIOGEOQUÍMICA}

\section{Transporte a larga distancia, formación del sue-} lo - Nivel universitario.

Aunque los ciclos biogeoquímicos usualmente se estudian a escala de micro-cuenca, teniendo en cuenta principalmente entradas atmosféricas como la precipitación (mayormente en forma de lluvia; menos estudiada en forma de nieve y neblina), existen otras entradas atmosféricas, como el transporte de aerosoles y partículas a largas distancias, y el vulcanismo e incendios, que pueden estar influenciando enormemente la dinámica de nutrientes del ecosistema, y que poco han sido estudiados ${ }^{126}$. Es así qué, los aportes de nutrientes a un ecosistema particular local, pueden estar vinculados a fenómenos de escala global. Por ejemplo, para el sur de Chile (entre $40^{\circ} \mathrm{S}$ a $42^{\circ} \mathrm{S}$ ), el aporte de aerosoles y sales marinas disueltas, en la masa de aire que constituye la corriente circumpolar antártica, es de gran importancia, particularmente en la Cordillera de la $\mathrm{Costa}^{126}$. Un ejemplo clásico de transportes a larga distancia, se registra en ecosistemas tropicales, donde la arena del Sahara es transportada en grandes cantidades hasta ecosistemas como arrecifes coralinos del Caribe, o a bosques de la intersección Andes-Amazonas en Ecuador, donde estos bosques derivan gran parte de su calcio, 
magnesio, y potasio, de esta arena ${ }^{127}$. Otro aporte de nutrientes particularmente importante para el sur de Chile, está dado por eventos volcánicos e incendios $^{126}$, que tampoco han sido muy considerados en el modelado de la dinámica de nutrientes de los ecosistemas terrestres. Falta comprender la interacción entre estos procesos y la diversidad y funciones de los hongos del suelo.

La meteorización biogénica es el proceso físico-químico, mediante el cual las rocas son degradadas por la acción directa o indirecta de la biota ${ }^{128}$. En el caso particular del suelo, las rocas degradadas corresponden al material parental (corteza terrestre), cuya composición mineral varía alrededor del planeta, pero del que hasta hace apenas dos décadas se pensaba que era degradado o meteorizado solamente por procesos físicos y químicos ${ }^{128}$. Sin embargo, la meteorización del material parental depende en gran medida del edafón o biota del suelo, particularmente de hongos micorrícicos ${ }^{126}$, especialmente en ecosistemas desarrollados, como bosques maduros de lento crecimiento. Durante la sucesión biológica y antes de alcanzar un estado de madurez, sin embargo, se ha demostrado que otros organismos como bacterias y archaeas también son capaces de meteorizar el material parental ${ }^{129}$. Para los hongos micorrícicos, la meteorización biogénica puede implicar (proceso activo) o no (proceso pasivo), un gasto energético; se implica un gasto energético cuando el proceso se realiza activamente mediante producción de ácidos orgánicos o transporte de agua en las hifas (por genes de aquaporinas), siendo este proceso más común cuando los nutrientes en el suelo son escasos $^{130}$, mientras que el proceso es pasivo, principalmente mediante la liberación de metabolitos secundarios (como ácidos y desechos de diferente tipo) tanto del hongo como de la planta, proceso que ocurre principalmente cuando el suelo no presenta deficiencia de nutrientes ${ }^{130}$. En un trabajo reciente de meteorización biogénica por micorrizas a escala global, se ha descubierto que las ecto- micorrizas en general tienen mayor capacidad de meteorizar el material parental que las micorrizas arbusculares ${ }^{130}$. En Chile, existen proyectos en curso encaminados a entender cómo, mediante procesos como la meteorización biogénica del material parental por parte de las micorrizas, los hongos ayudan a la formación del suelo y a dar forma a la superficie terrestre (http://earthshape.net).

Integración de diversidad fúngica a ciclos de $\mathbf{C}$, $\mathbf{N}, \mathbf{P}, \mathbf{y}$ otros nutrientes - Nivel universitario.

El estudio de los ciclos biogeoquímicos implica diversas áreas: ciencias del suelo, bioquímica, y ecología de comunidades. Una aproximación ecosistémica para entender cómo la diversidad afecta y es afectada por diversos procesos biogeoquímicos, debiera integrar holísticamente estas áreas. Sin embargo, este no suele ser el caso. Usualmente, desde las ciencias del suelo (agronomía, geología), poco se tienen en cuenta diferentes medidas de diversidad microbiológica y en general lo complejo y multidimensional de una comunidad microbiológica; desde la bioquímica el foco suelen ser procesos de diversidad funcional, sin tener en cuenta procesos o reglas de ensamblaje comunitario de los microorganismos que lleven a diversas funciones (o sus redundancias); y desde la ecología de comunidades del edafón no se suelen mirar las otras dos áreas mencionadas. La gran mayoría de la investigación en estas áreas diversas, se ha dado estableciendo correlaciones que no necesariamente implican relaciones causales en diferentes escalas de estudio (suelo, fisiología/bioquímica, diversidad, ecosistemas). Recientemente, se han definido 63 prioridades de investigación en ecología del suelo, que podrían dar luces de cómo integrar estas áreas diversas ${ }^{131}$, particularmente se ha preguntado sí: - ¿Se pueden mejorar los modelos de los procesos biogeoquímicos al incluir información referente a los organismos del suelo presentes ? $^{131}$

- ¿Se pueden predecir las funciones ecosistémicas a partir de la composición de caracteres de las comunidades del suelo? ${ }^{131}$ 
- ¿Cómo contribuye la biodiversidad del suelo y las interacciones ecológicas en el suelo a múltiples servicios ecosistémicos, como el secuestro de carbono, la supresión de enfermedades, y el mantenimiento de la biodiversidad aérea? ${ }^{131}$

Estas preguntas apuntan a direcciones de investigación. Por ejemplo, en un meta-análisis de literatura publicada ${ }^{132}$ se modelaron diferentes flujos de los ciclos del carbono y del nitrógeno, y se descubrió que al incluir diferentes medidas de diversidad microbiana (algunas de las vistas acá: estructura comunitaria, diversidad alfa, diversidad funcional), los modelos explicando cada flujo tenían mayor poder explicativo comparados a modelos que sólo incluían variables ambientales y edáficas. Así mismo, se señalan algunas de las vías para relacionar causalmente las diferentes mediciones realizadas $^{133}$ : las variables ambientales/edáficas se relacionan directamente al flujo biogeoquímico medido, así como a los diferentes tipos de diversidad; las diversidades alfa y filogenética se pueden relacionar a la estructura comunitaria y a sus redes de interacciones ecológicas (que constituyen propiedades emergentes de la comunidad); y estas últimas se pueden relacionar a una o más medidas de diversidad funcional microbiana, que finalmente tendrá un mayor impacto sobre el flujo biogeoquímico medido que los otros tipos de diversidad $^{133}$. Específicamente, para el caso de los hongos del suelo, como las micorrizas, recientes propuestas han surgido en cómo integrar su diversidad, especialmente diversidad funcional, a diversos procesos biogeoquímicos ${ }^{134}$, con aplicaciones en agroecosistemas ${ }^{135}$, o en ecosistemas urbanos ${ }^{136}$.

\section{Biogeoquímica - Tomadores de decisiones.}

La diversidad biológica se mide desde los genes hasta los ecosistemas, con diferentes métricas, y no consiste sólo en el número de especies sino que además incluye su abundancia, su historia evolutiva, y la diversidad de sus funciones. Una línea de investigación reciente busca entender cómo estas diferentes formas de medir la diversidad biológica, afectan y son afectadas por los ciclos y reciclaje de nutrientes en los ecosistemas terrestres, donde los hongos juegan un rol fundamental (Tabla 1). Así mismo, los hongos del suelo son vitales en dar forma al suelo, mediante la degradación de las rocas que constituyen la corteza terrestre.

\section{Biogeoquímica - Educación secundaria/Público general.}

Los hongos del suelo, como las micorrizas y los hongos descomponedores de hojas y materia orgánica, son de vital importancia para el transporte, reciclaje, y aprovechamiento de nutrientes esenciales (carbono, nitrógeno, fósforo, potasio, sodio, magnesio, entre otros) para las plantas, animales, y otros organismos (Tabla 1). Los hongos del suelo también ayudan a su formación, mediante la degradación de las rocas de la corteza terrestre.

\section{CONCLUSIÓN}

Aunque los roles de los hongos en los ciclos de nutrientes están bien documentados, los conceptos y marcos teóricos relacionados a dichos roles se suelen enseñar, en todos los niveles de formación y públicos, de forma dispersa entre diferentes áreas del conocimiento. Debiera entonces existir una visión holística de los procesos biogeoquímicos, y del rol de los hongos en los mismos, que integre conceptos base de física y química del suelo, además de bioquímica de diferentes procesos edáficos, con un conocimiento un poco más especializado sobre la ecología de comunidades de hongos del suelo y las diferentes medidas de diversidad y estructura microbiana, para finalmente llegar a un conocimiento avanzado de las interacciones ecosistema-plantas-suelo. La comprensión de los roles ecológicos de los hongos en el suelo, debería partir de la base de que estos afectan y son afectados tanto por las características físico-químicas del suelo, como por los procesos biogeoquímicos, debiera darse en un contexto holístico de integración multidisciplinar, y el nivel de 
Conceptos fundamentales en ecología de hongos del suelo: una propuesta pedagógica y de divulgación. - Marín C.

especialización del conocimiento debiera darse hacia niveles superiores de la jerarquía biológica, es decir, conocer más en detalle la ecología de ecosistemas y comunidades que la de poblaciones y organismos.

\section{AGRADECIMIENTOS}

Agradezco financiación de la Beca de Doctorado Nacional CONICYT (Folio No. 21150047).

\section{REFERENCIAS}

1. Brundrett MC. Coevolution of roots and mycorrhizas of land plants. New Phytol. 2002; 154(2):275304. DOI: $10.1046 / j .1469-8137.2002 .00397 . x$

2. Brundrett MC, Tedersoo L. Evolutionary history of mycorrhizal symbioses and global host plant diversity. New Phytol. 2018; (en prensa). DOI: $10.1111 /$ nph. 14976

3. Strullu-Derrien C, Selosse MA, Kenrick P, Martin FM. The origin and evolution of mycorrhizal symbioses: from palaeomycology to phylogenomics. New Phytol. 2018; (en prensa). DOI: 10.1111/nph.15076

4. Hawksworth DL, Lücking R. Fungal diversity revisited: 2.2 to 3.8 million species. Microbiol. Spectrum 2017; 5(4):1-17. DOI: 10.1128/microbiolspec.FUNK-0052-2016

5. Robledo GL, Rajchenberg M. South American polypores: first annotated checklist from Argentinean Yungas. Mycotaxon 2007; 100:5-9.

\section{Jiang Y, Wang W, Xie Q, Liu N, Liu L, Wang} D, et al. Plants transfer lipids to sustain colonization by mutualistic mycorrhizal and parasitic fungi. Science 2017; 356(6343):1172-1175. DOI: 10.1126/science.aam 9970

7. Keymer A, Pimprikar P, Wewer V, Huber C, Brands M, Bucerius SL, et al. Lipid transfer from plants to arbuscular mycorrhiza fungi. Elife 2017; 6:e29107. DOI: 10.7554/eLife.29107

8. Luginbuehl LH, Menard GN, Kurup S, van Erp H, Radhakrishnan GV, Breakspear A, et al.
Fatty acids in arbuscular mycorrhizal fungi are synthesized by the host plant. Science 2017;356(6343): 1175-1178. DOI: 10.1126/science.aan0081

9. Palfner G. Austrobasidium, a new gall-forming genus of Exobasidiaceae (Exobasidiales, Basidiomycota) on Hydrangea serratifolia from Chile. Aust. Syst. Bot. 2006; 19(5):431-436. DOI: 10.1071/SB05026

10. Palfner G, Valenzuela-Muñoz V, Gallardo-Escarate C, Parra LE, Becerra J, Silva M. Cordyceps cuncunae (Ascomycota, Hypocreales), a new pleoanamorphic species from temperate rainforest in southern Chile. Mycol. Prog. 2012; 11(3):733-739. DOI: 10.1007/s11557-011-0784-8

11. Steubing L, Godoy R, Alberdi M. Métodos de Ecología Vegetal. Santiago: Editorial Universitaria; 2002. $345 \mathrm{p}$.

12. Darwin C. The Formation of Vegetable Mould through the Action of Worms. London: John $\mathrm{Mu}-$ rray; $1881.326 \mathrm{p}$.

13. IUSS Working Group WRB. Base referencial mundial del recurso suelo 2014, Actualización 2015. Sistema internacional de clasificación de suelos para la nomenclatura de suelos y la creación de leyendas de mapas de suelos. Informes sobre recursos mundiales de suelos 106. Roma: FAO; 2015. $205 \mathrm{p}$.

14. Tedersoo L, Bahram M, Põlme S, Kõljalg $\mathrm{U}$, Yorou NS, Wijesundera R, et al. Global diversity and geography of soil fungi. Science 2014; 346(6213):1256688. DOI: 10.1126/science. 1256688 
15. Tedersoo L, Sánchez-Ramírez S, Kõljalg U, Bahram M, Döring M, Schigel D, et al. High-level classification of the Fungi and a tool for evolutionary ecological analyses. Fungal Div. 2018; (in press). Doi: 10.1007/s13225-018-0401-0

16. Davison J, Moora M, Öpik M, Adholeya A, Ainsaar L, Bâ A, et al. Global assessment of arbuscular mycorrhizal fungus diversity reveals very low endemism. Science 2015; 349(6251):970-973. DOI: $10.1126 /$ science.aab1161

17. Marín C, Godoy R, Valenzuela E, Schloter M, Wubet T, Boy J, et al. Functional landuse change effects on soil fungal communities on Chilean temperate rainforests. J. Soil Sci. Plant Nutr. 2017a; 17(4):985-1002. DOI: 10.4067/ S071895162017000400011

18. Marín C, Aguilera P, Cornejo P, Godoy R, Oehl F, Palfner G, et al. Arbuscular mycorrhizal assemblages along contrasting Andean forests of southern Chile. J. Soil Sci. Plant Nutr. 2016; 16(4):916-929. DOI: 10.4067/ S071895162016005000065

19. Marín C, Aguilera P, Oehl F, Godoy R. Factors affecting arbuscular mycorrhizal fungi of Chilean temperate rainforests. J. Soil Sci. Plant Nutr. 2017b; 17(4):966-984. DOI: 10.4067/ S071895162017000400010

20. Huang Q. Soil Biochemestry. In: Verheye WH, editor. Land Use, Land Cover and Soil Sciences - Volume VI: Soils and Soil Sciences. Paris: Encyclopedia of Life Support Systems (EOLSS); 2009. p. 205-232.

21. He Z, Gentry TJ, Schadt CW, Wu L, Liebich J, Chong SC, et al. GeoChip: a comprehensive microarray for investigating biogeochemical, ecological and environmental processes. ISME J. 2007; 1(1):67-77. DOI: 10.1038/ismej.2007.2
22. Paul EA. Soil Microbiology, Ecology and Biochemistry. Burlington: Academic Press; 2014. 514 p.

23. Larsen J, Olsson PA, Jakobsen I. The use of fatty acid signatures to study mycelial interactions between the arbuscular mycorrhizal fungus Glomus intraradices and the saprotrophic fungus Fusarium culmorum in root-free soil. Mycol. Res. 1998; 102(12):1491-1496. DOI: 10.1017/ S0953756298006558

24. Bååth $\mathbf{E}$. The use of neutral lipid fatty acids to indicate the physiological conditions of soil fungi. Microb. Ecol. 2003; 45(4):373-383. DOI: 10.1007/ s00248-003-2002-y

25. Orgiazzi A, Bardgett RD, Barrios E, BehanPelletier V, Briones MJI, Chotte JL, et al. Global Soil Biodiversity Atlas. Luxembourg: European Comission; 2016. 176 p.

26. Fortuna A. The Soil Biota. Nature Educ. Know. 2012; 3(10):1.

27. Lewontin RC. The units of selection. Ann. Rev. Ecol. Syst. 1970; 1(1):1-18. DOI: 10.1146/ annurev.es.01.110170.000245

28. Marín C. Selección Multinivel: historia, modelos, debates, y principalmente, evidencias empíricas. EVOLUCIÓN: Revista de la Sociedad Española de Biología Evolutiva 2015; 10(2):51-70

29. Marín C. The levels of selection debate: taking into account existing empirical evidence. Acta Biol. Col. 2016; 21(3):467-472. DOI: 10.15446/ abc.v21n3.54596

30. Okasha S. Evolution and the Levels of Selection. New York: Oxford Univ. Press; 2006. 288 p.

31. Darwin CR. On the Origin of Species by means of Natural Selection or the Preservation of 
Favoured Races in the Struggle for Life. London: John Murray; 1859. 502 p.

32. Folse III HJ, Roughgarden J. What is an individual organism? A multilevel selection perspective. Q. Rev. Biol. 2010; 85(4):447-472. DOI: $10.1086 / 656905$

33. Theis KR, Dheilly NM, Klassen JL, Brucker RM, Baines JF, Bosch TC, et al. Getting the hologenome concept right: an eco-evolutionary framework for hosts and their microbiomes. Msystems 2016; 1(2):e00028-16. DOI: 10.1128/mSystems.00028-16

34. Gaggiotti OE, Chao A, PeresNeto P, Chiu CH, Edwards C, Fortin MJ, et al. Diversity from genes to ecosystems: A unifying framework to study variation across biological metrics and scales. Evol. Appl. 2018; (in press). DOI: 10.1111/ eva. 12593

35. Swenson W, Wilson DS, Elias R. Artificial ecosystem selection. Proc. Natl. Acad. Sci. USA 2000; 97(16):9110-9114. DOI: 10.1073/ pnas. 150237597

36. Swenson W, Arendt J, Wilson DS. Artificial selection of microbial ecosystems for 3-chloroaniline biodegradation. Environm. Microbiol. 2000; 2(5):564-571. DOI: 10.1046/j.14622920.2000.00 140.x

37. Koschwanez J, Foster KR, Murray AJ. Sucrose utilization in budding yeast as a model for the origin of undifferentiated multi-cellularity. Plos Biol. 2011; 9(8):e1001122. DOI: 10.1371/ journal.pbio.1001122

38. Koschwanez J, Foster KR, Murray AJ. Improved use of a public good selects for the evolution of undifferentiated multi-cellularity. eLife 2013; 2:e00367. DOI: 10.7554/eLife.00367
39. Ratcliff WC, Denison RF, Borrello M, Travisano M. Experimental evolution of multicellularity. Proc. Natl. Acad. Sci. USA 2012; 109(5):15951600. DOI: $10.1073 /$ pnas.1115323109

40. Ratcliff WC, Pentz JT, Travisano M. Tempo and mode of multicellular adaptation in experimentally evolved Saccharomyces cerevisiae. Evolution 2013; 67(6):1573-1581. DOI: 10.1111/evo.12101

41. Sanders IR. Ecology and evolution of multigenomic arbuscular mycorrhizal fungi. Am. Nat. 2002; 160(S4):S128-S141. DOI: 10.1086/342085

42. Rosendahl S. Communities, populations and individuals of arbuscular mycorrhizal fungi. New Phytol. 2008; 178(2):253-266. DOI: 10.1111/j.1469-8137.2008.02378.x

43. Maheshwari R. The largest and oldest living organism. Resonance 2005; 10(4): 4-9.

44. Leake JR. The biology of mycoheterotrophic ('saprophytic') plants. New Phytol. 1994; 127(2):171-216. DOI: 10.1111/j.1469-8137.1994. tb04272.x

45. Taylor DL, Bruns TD, Leake JR, Read DJ. Mycorrhizal specificity and function in myco-heterotrophic plants. In: van der Heidjen MGA, Sanders IR, editors. Mycorrhizal Ecology. Heidelberg: Springer Berlin; 2002. p. 375-413.

46. Hynson NA, Bruns TD. Fungal hosts for mycoheterotrophic plants: a nonexclusive, but highly selective club. New Phytol. 2010; 185(3):598-601. DOI: $10.1111 /$ j.1469-8137.2009.03152.x

47. Courty PE, Walder F, Boller T, Ineichen K, Wiemken A, Rousteau A, et al. Carbon and nitrogen metabolism in mycorrhizal networks and mycoheterotrophic plants of tropical forests: a stable isotope analysis. Plant Physiol. 2011; 
Conceptos fundamentales en ecología de hongos del suelo: una propuesta pedagógica y de divulgación. - Marín C.

156(2):952-961. DOI: 10.1104/pp.111.177618

48. Shaw TM, Dighton J, Sanders FE. Interactions between ectomycorrhizal and saprotrophic fungi on agar and in association with seedlings of lodgepole pine (Pinus contorta). Mycol. Res. 1995; 99(2):159-165. DOI: $10.1016 /$ S09537562(09)80880-0

49. Hobbie EA, Macko SA, Shugart HH. Insights into nitrogen and carbon dynamics of ectomycorrhizal and saprotrophic fungi from isotopic evidence. Oecologia 1999; 118(3):353-360. DOI: $10.1007 / \mathrm{s} 004420050736$

50. Högberg MN, Bååth E, Nordgren A, Arnebrant K, Högberg P. Contrasting effects of nitrogen availability on plant carbon supply to mycorrhizal fungi and saprotrophs-a hypothesis based on field observations in boreal forest. New Phytol. 2003; 160(1):225-238. DOI: 10.1046/j.14698137.2003.00867.x

51. Lindahl BD, Ihrmark K, Boberg J, Trumbore SE, Högberg P, Stenlid J, et al. Spatial separation of litter decomposition and mycorrhizal nitrogen uptake in a boreal forest. New Phytol. 2007; 173(3):611-620. DOI: 10.1111/j.14698137.2006.01936.x

52. Bödeker I, Clemmensen KE, Boer W, Martin F, Olson Å, Lindah BD. Ectomycorrhizal Cortinarius species participate in enzymatic oxidation of humus in northern forest ecosystems. New Phytol. 2014; 203(1):245-256. DOI: 10.1111/ nph.12791

53. Bödeker I, Lindahl BD, Olson Å, Clemmensen KE. Mycorrhizal and saprotrophic fungal guilds compete for the same organic substrates but affect decomposition differently. Funct. Ecol. 2016; 30(12):1967-1978. DOI: 10.1111/13652435.12677
54. Lindahl BD, Tunlid A. Ectomycorrhizal fungi-potential organic matter decomposers, yet not saprotrophs. New Phytol. 2015; 205(4):14431447. DOI: $10.1111 / \mathrm{nph} .13201$

55. Fernandez CW, Kennedy PG. Revisiting the 'Gadgil effect': do interguild fungal interactions control carbon cycling in forest soils?. New Phytol. 2016; 209(4):1382-1394. DOI: 10.1111/nph.13648

56. Kindt R, Coe R. Tree diversity analysis: a manual and software for common statistical methods for ecological and biodiversity studies. Nairobi: World Agroforestry Centre; 2005. 196 p.

57. Aguilera P, Marín C, Oehl F, Godoy R, Borie $\mathbf{F}$, Cornejo P. Selection of aluminum tolerant cereal genotypes strongly influences the arbuscular mycorrhizal fungal communities in an acidic Andosol. Agric. Ecosyst. Env. 2017; 246:86-93. DOI: 10.1016/j.agee.2017.05.031

58. Petchey OL, Gaston KJ. Functional diversity: back to basics and looking forward. Ecol. Lett. 2006; 9(6):741-758. DOI: 10.1111/j.14610248.2006.00924.x

59. Zak JC, Willig MR, Moorhead DL, Wildman HG. Functional diversity of microbial communities: a quantitative approach. Soil Biol. Biochem. 1994; 26(9):1101-1108. DOI: 10.1016/00380717(94)90131-7

60. Hultman J, Waldrop MP, Mackelprang R, David MM, McFarland J, Blazewicz SJ, et al. Multi-omics of permafrost, active layer and thermokarst bog soil microbiomes. Nature 2015; 521(7551):208-212. DOI: 10.1038/nature14238

61. Faith DP. Conservation evaluation and phylogenetic diversity. Biol. Conserv. 1992; 61(1):1-10. DOI: 10.1016/0006-3207(92)91201-3

62. Davison J, Moora M, Jairus T, Vasar M, 
Öpik M, Zobel M. Hierarchical assembly rules in arbuscular mycorrhizal (AM) fungal communities. Soil Biol. Biochem. 2016; 97: 63-70. DOI: 10.1016/j.soilbio.2016.03.003

63. Barberán A, Bates ST, Casamayor EO, Fierer N. Using network analysis to explore cooccurrence patterns in soil microbial communities. ISME J. 2012; 6(2):343-351. DOI: 10.1038/ ismej.2011.119

64. Berry D, Widder S. Deciphering microbial interactions and detecting keystone species with co-occurrence networks. Front. Microbiol. 2014; 5:219. DOI: $10.3389 /$ fmicb.2014.00219

65. Williams RJ, Howe A, Hofmockel KS. Demonstrating microbial co-occurrence pattern analyses within and between ecosystems. Front. Microbiol. 2014; 5:358. DOI: 10.3389/fmicb.2014.00358

66. Morales-Castilla I, Matias MG, Gravel D, Araújo MB. Inferring biotic interactions from proxies. Trends Ecol. Evol. 2015; 30(6):347-356. DOI: $10.1016 /$ j.tree.2015.03.014

67. Faust K, Sathirapongsasuti JF, Izard J, Segata N, Gevers D, Raes J, et al. Microbial co-occurrence relationships in the human microbiome. Plos Comput. Biol. 2012; 8(7):e1002606. DOI: 10.1371/journal.pcbi.1002606

68. Pérez-Valera E, Goberna M, Faust K, Raes J, García C, Verdú M. Fire modifies the phylogenetic structure of soil bacterial co occurrence networks. Environm. Microbiol. 2017; 19(1):317327. DOI: $10.1111 / 1462-2920.13609$

69. Nguyen NH, Song Z, Bates ST, Branco S, Tedersoo L, Menke J, et al. FUNGuild: An open annotation tool for parsing fungal community datasets by ecological guild. Fungal Ecol. 2016;
20:241-248. DOI: 10.1016/j.funeco.2015.06.006

70. Lindahl BD, Nilsson RH, Tedersoo L, Abarenkov $\mathrm{K}$, Carlsen $\mathrm{T}$, Kjøller $\mathrm{R}$, et al. Fungal community analysis by high-throughput sequencing of amplified markers-a user's guide. New Phytol. 2013; 199(1):288-299. DOI: 10.1111/ nph.12243

71. Tedersoo L, Tooming-Klunderud A, Anslan S. PacBio metabarcoding of Fungi and other eukaryotes: errors, biases and perspectives. New Phytol. 2018; 217(3):1370-1385. DOI: 10.1111/nph.14776

72. Öpik M, Vanatoa A, Vanatoa E, Moora M, Davison J, Kalwij JM, et al. The online database MaarjAM reveals global and ecosystemic distribution patterns in arbuscular mycorrhizal fungi (Glomeromycota). New Phytol. 2010; 188(1):223-241. DOI: $10.1111 /$ j.14698137.2010.03334.x

73. Bokulich NA, Mills DA. Improved selection of internal transcribed spacer-specific primers enables quantitative, ultra-high-throughput profiling of fungal communities. Appl. Environm. Microbiol. 2013; 79(8):2519-2526. DOI: 10.1128/ AEM.03870-12

74. Kõljalg U, Nilsson RH, Abarenkov K, Tedersoo L, Taylor AF, Bahram M, et al. Towards a unified paradigm for sequence based identification of fungi. Mol. Ecol. 2013; 22(21): 5271-5277. DOI: $10.1111 / \mathrm{mec} .12481$

75. Ihrmark K, Bödeker ITM, Cruz-Martinez K, Friberg H, Kubartova A, Schenck J, et $\boldsymbol{a l}$. New primers to amplify the fungal ITS2 region -evaluation by 454-sequencing of artificial and natural communities. FEMS Microbiol. Ecol. 2012; 82(3):666-677. DOI: 10.1111/j.15746941.2012.01437.x

76. Swenson NG. Functional and Phylogenetic Ecology in R. New York: Springer; 2014. 201 p. 
Conceptos fundamentales en ecología de hongos del suelo: una propuesta pedagógica y de divulgación. - Marín C.

77. RStudio Team. RStudio: Integrated Development for R. Boston: RStudio, Inc.; 2016. URL: http://www.rstudio.com/.

78. Wickham H. ggplot2: elegant graphics for data analysis. Houston: Springer; 2016. 260 p.

79. Albert J. Bayesian Computation with R. New York: Springer; 2007. 267 p.

80. Stevens MHH. A Primer of Ecology with R. New York: Springer; 2009. 401 p.

81. Everitt B, Hothorn T. An Introduction to Applied Multivariate Analysis with R. New York: Springer; 2011.273 p.

82. Paradis E. Analysis of Phylogenetics and Evolution with R. 2nd edition. New York: Springer; 2012. 386 p.

83. United Nations (UN). Convention on Biological Diversity. Rio de Janeiro: UN; 1992. 28 p.

84. Food and Agriculture Organization of the United Nations (FAO). International Treaty on Plant Genetic Resources for Food and Agriculture. Madrid: FAO; 2001. 56 p.

85. United Nations (UN). Transforming our world: the 2030 Agenda for Sustainable Development. New York: UN; 2015. 35 p.

86. Read DJ. Mycorrhizas in ecosystems. Experientia 1991; 47(4):376-391. DOI: 10.1007/ BF01972080

87. Tedersoo L, Brundrett MC. Evolution of ectomycorrhizal symbiosis in plants. In: Tedersoo L, editor. Biogeography of Mycorrhizal Symbiosis. Cham: Springer; 2017. p. 407-467.

88. Leake JR. Plants parasitic on fungi: unear- thing the fungi in myco-heterotrophs and debunking the 'saprophytic'plant myth. Mycologist 2005; 19(3):113-122. DOIoi: 10.1017/ S0269915X(05)00304-6

89. Berg B, Laskowski R. Advances in ecological research Vol. 38. Litter decomposition: A guide to carbon and nutrient turnover. Burlington: Academic Press; 2006. 421 p.

90. Berg B, McClaugherty C. Plant litter: decomposition, humus formation, carbon sequestration. Berlin: Springer-Verlag; 2014. 315 p.

91. Graça MA, Bärlocher F, Gessner MO. Methods to study litter decomposition: a practical guide. Amsterdam: Springer Netherlands; 2005. 329 p.

92. Varma A. Mycorrhiza: state of the art, genetics and molecular biology, eco-function, biotechnology, eco-physiology, structure and systematics. Berlin: Springer-Verlag; 2008. 797 p.

93. Smith SE, Read DJ. Mycorrhizal symbiosis. 3rd Edition. Burlington: Academic Press; 2008. $800 \mathrm{p}$.

94. Varma A, Prasad R, Tuteja N. MycorrhizaEco-Physiology, Secondary Metabolites, Nanomaterials. Fourth Edition. Cham: Springer; 2017. 334 p.

95. Varma A, Prasad R, Tuteja N. MycorrhizaFunction, Diversity, State of the Art. Cham: Springer; 2017. 394 p.

96. Wu QS. Arbuscular mycorrhizas and stress tolerance of plants. Singapore: Springer; 2017. 327 p.

97. Mendgen K, Hahn M, Deising H. Morphogenesis and mechanisms of penetration by 
plant pathogenic fungi. Annu. Rev. Phytopathol. 1996; 34(1):367-386. DOI: 10.1146/annurev. phyto.34.1.367

98. Dean R, van Kan JA, Pretorius ZA, Hammond-Kosack KE, di Pietro A, Spanu PD, et al. The Top 10 fungal pathogens in molecular plant pathology. Mol. Plant pathol. 2012; 13(4):414430. DOI: 10.1111/j.1364-3703.2011.00783.x

99. Doehlemann G, Ökmen B, Zhu W, Sharon A. Plant Pathogenic Fungi. Microbiol. Spectrum 2017; 5(1). DOI: 10.1128/microbiolspec.FUNK0023-2016

100. Moora M. Mycorrhizal traits and plant communities: perspectives for integration. J. Veg. Sci. 2014; 25(5):1126-1132. DOI: 10.1111/jvs. 12177

101. Swaty R, Michael HM, Deckert R, Gehring CA. Mapping the potential mycorrhizal associations of the conterminous United States of America. Fungal Ecol. 2016; 24(B):139-147. DOI: 10.1016/j.funeco.2016.05.005

102. Soudzilovskaia NA, Douma JC, Akhmetzhanova AA, Bodegom PM, Cornwell WK, Moens EJ, et al. Global patterns of plant root colonization intensity by mycorrhizal fungi explained by climate and soil chemistry. Glob. Ecol. Biogeogr. 2015; 24(3):371-382. DOI: 10.1111/geb.12272

103. Menzel A, Hempel S, Manceur AM, Götzenberger L, Moora M, Rillig MC, et al. Distribution patterns of arbuscular mycorrhizal and non-mycorrhizal plant species in Germany. Perspect. Plant Ecol. 2016; 21:78-88. DOI: 10.1016/j. ppees.2016.06.002

104. Bueno CG, Moora M, Gerz M, Davison J, Öpik M, Pärtel M, et al. Plant mycorrhizal status, but not type, shifts with latitude and elevation in Europe. Glob. Ecol. Biogeogr. 2017; 26(6):690-
699. DOI: $10.1111 /$ geb. 12582

105. Gerz M, Bueno CG, Zobel M, Moora M. Plant community mycorrhization in temperate forests and grasslands: relations with edaphic properties and plant diversity. J. Veg. Sci. 2016; 27(1):8999. DOI: $10.1111 /$ jvs. 12338

106. Gazol A, Zobel M, Cantero JJ, Davison J, Esler KJ, Jairus T, et al. Impact of alien pines on local arbuscular mycorrhizal fungal communities-evidence from two continents. FEMS Microbiol. Ecol. 2016; 92(6):fiw073. DOI: 10.1093/ femsec/fiw073

107. Dickie IA, Nuñes MA, Pringle A, Lebel T, Tourtellot SG, Johnston PR. Towards management of invasive ectomycorrhizal fungi. Biolo. Invasions. 2016; 18(12):3383-3395. DOI: 10.1007/ s10530-016-1243-x

108. Nuñez MA, Horton TR, Simberloff D. Lack of belowground mutualisms hinders Pinaceae invasions. Ecology 2009; 90(9):2352-2359. DOIi: $10.1890 / 08-2139.1$

109. Nuñez MA, Hayward J, Horton TR, Amico GC, Dimarco RD, Barrios-Garcia MN, et al. Exotic mammals disperse exotic fungi that promote invasion by exotic trees. Plos One 2013; 8(6):e66832. DI: 10.1371/journal.pone.0066832

110. Liebhold AM, Brockerhoff EG, Kalisz S, Nuñez MA, Wardle DA, Wingfield MJ. Biological invasions in forest ecosystems. Biol. Invasions. 2017; 19(11):3437-3458. DOI: 10.1007/s10530017-1458-5

111. Policelli N, Chiuffo MC, Moyano J, Torres A, Rodriguez-Cabal MA, Nuñez MA. Pathogen accumulation cannot undo the impact of invasive species. Biol. Invasions 2018; 20(1):1-4. DOI: 10.1007/s10530-017-1439-8 
112. Frey-Klett P, Garbaye J. Mycorrhiza helper bacteria: a promising model for the genomic analysis of fungal-bacterial interactions. New Phytol. 2015; 168(1):4-8. DOI: 10.1111/j.14698137.2005.01553.x

113. Artursson V, Finlay RD, Jansson JK. Interactions between arbuscular mycorrhizal fungi and bacteria and their potential for stimulating plant growth. Environ. Microbiol. 2006; 8(1):1-10. DOI: 10.1111/j.1462-2920.2005.00942.x

114. Wargo MJ, Hogan DA. Fungal-bacterial interactions: a mixed bag of mingling microbes. Curr. Opin. Microbiol. 2006; 9(4):359-364. DOI: 10.1016/j.mib.2006.06.001

115. Ingham RE, Trofymow JA, Ingham ER, Coleman DC. Interactions of bacteria, fungi, and their nematode grazers: effects on nutrient cycling and plant growth. Ecol. Monogr. 1985; 55(1):119140. DOI: $10.2307 / 1942528$

116. Li H, Xiang D, Wang C, Li X, Lou Y. Effects of epigeic earthworm (Eisenia fetida) and arbuscular mycorrhizal fungus (Glomus intraradices) on enzyme activities of a sterilized soil-sand mixture and nutrient uptake by maize. Biol. Fertil. Soils. 2012; 48(8):879-887. DOI: 10.1007/s00374-0120679-0

117. Lawrence B, Fisk MC, Fahey TJ, Suárez ER. Influence of nonnative earthworms on mycorrhizal colonization of sugar maple (Acer saccharum). New Phytol. 2003; 157(1):145-153. DOI: 10.1046/j.1469-8137.2003.00649.x

118. Reddell P, Spain AV. Earthworms as vectors of viable propagules of mycorrhizal fungi. Soil Biol. Biochem. 1991; 23(8):767-774. DOI: 10.1016/0038-0717(91)90147-C

119. Yu X, Cheng J, Wong MH. Earthwormmycorrhiza interaction on $\mathrm{Cd}$ uptake and growth of ryegrass. Soil Biol. Biochem. 2005; 37(2):195201. DOI: $10.1016 /$ j.soilbio.2004.07.029

120. Bonfante P, Anca IA. Plants, mycorrhizal fungi, and bacteria: a network of interactions. Annual Rev. Microbiol. 2009; 63:363-383. Doi: 10.1146/annurev.micro.091208.073504

121. Deveau A, Bonito G, Uehling J, Paoletti M, Becker M, Bindschedler S, et al. Bacterial-Fungal Interactions: ecology, mechanisms and challenges. FEMS Microbiol. Rev 2018; (in press). DOI: 10.1093/femsre/fuy008

122. Worrich A, Stryhanyuk H, Musat N, König S, Banitz T, Centler F, et al. Mycelium-mediated transfer of water and nutrients stimulates bacterial activity in dry and oligotrophic environments. Nature Commun. 2017; 8:15472. DOI: 0.1038/ ncomms 15472

123. Koricheva J, Gange AC, Jones T. Effects of mycorrhizal fungi on insect herbivores: a metaanalysis. Ecology. 2009; 90(8):2088-2097. DOI: $10.1890 / 08-1555.1$

124. Gehring CA, Whitham TG. Mycorrhizaeherbivore interactions: population and community consequences. In: van der Heidjen MGA, Sanders IR, editors. Mycorrhizal Ecology. Heidelberg: Springer Berlin; 2002. p. 295-320.

125. Kula AA, Hartnett DC, Wilson GW. Effects of mycorrhizal symbiosis on tallgrass prairie plantherbivore interactions. Ecol. Lett. 2005; 8(1):6169. DOI: $10.1111 /$ j.14610248.2004.00690.x

126. Boy J, Godoy R, Guveara G. Transporte Aerosoles, Biometeorización y Cambio Global. En: Donoso-Zegers C, González ME, Lara A, editores. Ecologia Forestal: Bases para el Manejo Sustentable y Conservacion de los Bosques Nativos de Chile. Santiago: Editorial Cuneo; 2013. p. 281-295. 
127. Boy J, Wilcke W. Tropical Andean forest derives calcium and magnesium from Saharan dust. Global Biogeochem. Cycles. 2008; 22(1):GB1027. DOI: $10.1029 / 2007 \mathrm{~GB} 002960$

128. van Breemen $N$, Finlay $R$, Lundström $U$, Jongmans AG, Giesler R, Olsson M. Mycorrhizal weathering: a true case of mineral plant nutrition?. Biogeochemistry 2000; 49(1):53-67. DOI: 10.1023/A:1006256231670

129. Godoy R, Aguirre-Morales M, Boy J. Una ventana natural para investigar el desarrollo de la vida a través del tiempo. Boletín Antártico Chileno 2015; 34(2):16-18.

130. Boy J, Godoy R, Dechene A, Shibistova O, Amir H, Iskandar I, et al. Global comparison reveals biogenic weathering as driven by nutrient limitation at ecosystem scale. EGU General Assembly Conference Abstracts 2017; 19:14687.

131. Eisenhauer N, Antunes PM, Bennett AE, Birkhofer K, Bissett A, Bowker MA, et al. Priorities for research in soil ecology. Pedobiologia 2017; 63:1-7. DOI: 10.1016/j.pedobi.2017.05.003

132. Graham EB, Knelman JE, Schindlbacher A, Siciliano S, Breulmann M, Yannarell A, et al.
Microbes as engines of ecosystem function: when does community structure enhance predictions of ecosystem processes? Front. Microbiol. 2016; 7: 214. DOI: $10.3389 /$ fmicb.2016.00214

133. Hall E, Bernhardt ES, Bier RL, Bradford MA, Boot CM, Cotner JB, et al. Understanding how microbiomes influence the systems they inhabit: insight from ecosystem ecology. Preprint 2018; DOI ://doi.org/10.1101/065128

134. Wurzburger N, Clemmensen KE. From mycorrhizal fungal traits to ecosystem propertiesand back again. J. Ecol. 2018; 106(2):463-467. DOI: $10.1111 / 1365-2745.12922$

135. Treseder KK, Allen EB, Egerton-Warburton LM, Hart MM, Klironomos JN, Maherali $\mathbf{H}$, et al. Arbuscular mycorrhizal fungi as mediators of ecosystem responses to nitrogen deposition: A trait-based predictive framework. J. Ecol. 2018; 106(2):480-489. DOI: 10.1111/1365-2745.12919

136. Anne B, Geoffroy S, Cherel J, Warot G, Marie S, Noël CJ, et al. Towards an operational methodology to optimize ecosystem services provided by urban soils. Landscape Urban Plan. 2018; 176:1-9. DOI: 10.1016/j.landurbplan.2018.03.019 
Conceptos fundamentales en ecología de hongos del suelo: una propuesta pedagógica y de divulgación. - Marín C.

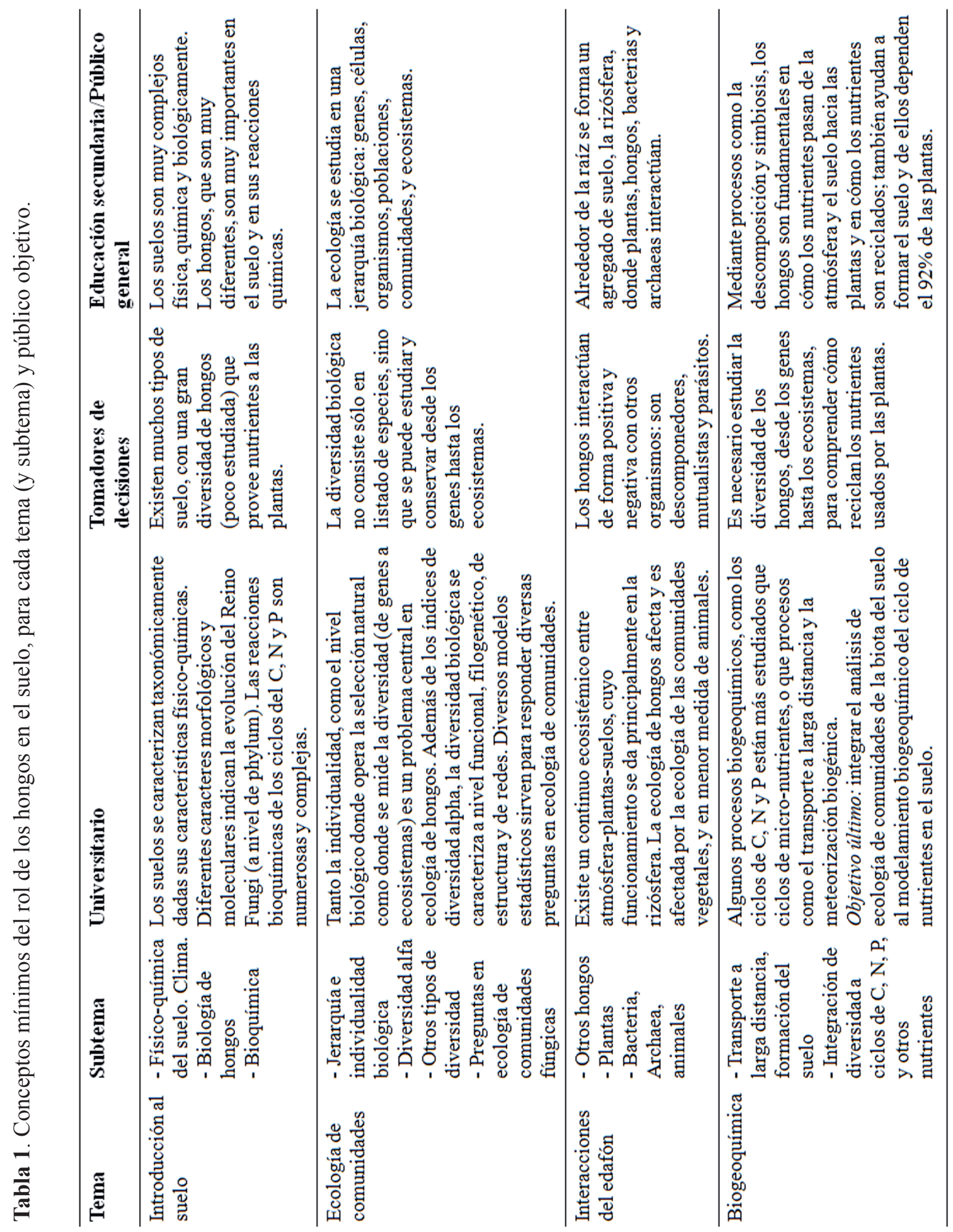

